\title{
The development and validation of the Cluster Headache Quality of life scale (CHQ)
}

\author{
Norazah Abu Bakar', Mariam Torkamani², Surat Tanprawate', Giorgio Lambru', Manjit Matharu \\ and Marjan Jahanshahi $2^{2^{*}}$
}

\begin{abstract}
Background: Cluster headache $(\mathrm{CH})$ is a rare, excruciating and highly disabling primary headache disorder. Using non cluster headache specific measures, previous studies have shown that $\mathrm{CH}$ has a significant negative impact on patients' quality of life (QoL), but a CH-specific QoL scale is currently unavailable. Thus, the objective of this study was to develop and validate a $\mathrm{CH}$-specific QoL scale.
\end{abstract}

Methods: Based on a literature review, semi-structured patient interviews and expert panel consultation, we produced a 54-item questionnaire, which was pre-tested in a sample of $\mathrm{CH}$ patients and subsequently reduced to 47 items. The revised scale was then administered to $\mathrm{CH}$ sufferers attending a tertiary headache clinic and those registered with a patient group. A total of 406 completed questionnaires were received. To assess test-retest reliability, a subsample $(N=56)$ completed the scale on a second occasion, two weeks after the first. Standard statistical methods were used to analyse the data for validity and reliability.

Results: Item reduction and exploratory factor analysis led to 28-items, grouped into four subscales labelled "restriction of activities of daily living", "impact on mood and interpersonal relationships", "pain and anxiety", and "lack of vitality". The final CH-specific QoL scale, the CHQ, demonstrated satisfactory internal consistency (Cronbach's alpha $>0.9$ ) and test-retest reliability (intraclass correlation coefficient $>0.8$ ), with good internal construct validity between subscales (range 0.52-0.75) and convergent validity with other QoL measures.

Conclusions: We have developed and validated the first patient-reported outcome measure of QoL specifically for $\mathrm{CH}$ sufferers, which may be used to monitor QoL in clinical care and research.

Keywords: Cluster headache, Trigeminal autonomic cephalalgia, Headache, Quality of life

Abbreviations: $\mathrm{ADL}$, Activities of daily living; BP, Bodily pain; $\mathrm{CCH}$, Chronic cluster headache; $\mathrm{CH}$, Cluster headache; $\mathrm{CHQ}$, Cluster headache specific quality of life; $\mathrm{ECH}$, Episodic cluster headache; $\mathrm{EF}$, Emotional role functioning; $\mathrm{EQ}-$ 5D, The European Quality of Life scale; GH, General health; HRQoL, Health related quality of life; ICHD, International Classification of Headache Disorders; MH, Mental health; MSQ, Migraine-Specific Quality of Life Questionnaire; OUCH-UK, The Organisation for the Understanding of Cluster Headache, United Kingdom; PF, Physical functioning; QoL, Quality of life; REM, Rapid eye movement; RP, Role-physical; SF, Social role functioning; SF-36, The Short Form 36-items Health Survey; SPSS-PASW, Statistical Package for the Social Sciences-Predictive Analytics Software; VAS, Visual analogue scale; VT, Vitality

\footnotetext{
*Correspondence: m.jahanshahi@ucl.ac.uk

${ }^{2}$ Cognitive Motor Neuroscience Group, Sobell Department of Motor

Neuroscience \& Movement Disorders, UCL Institute of Neurology and The

National Hospital for Neurology and Neurosurgery, Queen Square, London WC1N 3BG, UK

Full list of author information is available at the end of the article
} 


\section{Background}

Quality of life (QoL) scales have increasingly emerged as an important clinical outcome measure for assessing the impact of a disorder and its treatment on patients' wellbeing $[3,18]$. Within the headache field, much of the interest in this area has been focused on migraine, due to its high prevalence. A number of disease-specific QoL instruments have been developed for migraine [11, 14, 17, 23]. Similar measures for other primary headache types, such as cluster headache, are not yet available.

Cluster headache $(\mathrm{CH})$ is a rare, excruciating and highly disabling headache that is strictly lateralised, typically associated with prominent cranial autonomic features or a sense of restlessness or agitation [10, 12]. In $\mathrm{CH}$, assessment of QoL is currently limited to use of generic scales, such as the SF-36, and headache disability instruments, which have shown significantly diminished scores compared to headache-free controls [2, 5, 7, 16, 21]. Moreover, a study found significant differences between $\mathrm{CH}$ patients in the ictal versus the interictal period, but no significant differences between $\mathrm{CH}$ patients and migraineurs [7]. The authors postulated that since the study used a migraine-specific measure, it might not have been able to truly capture the essential aspects of $\mathrm{CH}$ [7]. In light of this and the differences between the two headache entities, we aim to develop a $\mathrm{CH}$-specific QoL tool, which may better reflect the true nature of the daily life impact of this highly disabling disorder. We report the development and validation of a disease-specific QoL instrument for $\mathrm{CH}$.

\section{Methods}

Ethical approval for this study was obtained from The North West London Research Ethics Committee (Date of ethics approval: 26 July 2010, Ethics ID number: 10/ H0722/43). Informed written consent was obtained from all participants prior to enrolment in the study. Data was collated in an electronic database and all statistical analyses were performed using SPSS-PASW software version 18. A three-step approach was employed in the development and validation of the scale: first item generation; second item reduction and scale development; and, finally scale validation and reliability testing.

\section{Item generation}

A comprehensive review of the literature was conducted and existing headache-specific QoL scales were studied to generate an overview of the areas of life impacted by $\mathrm{CH}$. This was followed by an in-depth semi-structured interview of 24 episodic and chronic $\mathrm{CH}$ patients in 2010 (M:F 2.6:1, mean age 46.3 years), diagnosed according to the diagnostic criteria of the International Classification of Headache Disorders (ICHD-II) [12], who are registered with the headache clinic at The National
Hospital for Neurology and Neurosurgery, London and were living in and around the Greater London area. The topics covered during the interview included pain characteristics, aspects of the patient's life that were affected by their headaches, their support system, and their outlook on life. These processes allowed generation of a preliminary questionnaire, which was then discussed with a panel of experts with an interest in headache. Any ambiguous or similar items were eliminated or grouped together, before a final set of items were agreed upon. A 54-item questionnaire was subsequently drafted, each with a range of five possible answers on a Likert scale: never, occasionally, sometimes, often and always, addressing areas of life impacted by $\mathrm{CH}$ within the past month or during their last cluster bout. A visual analogue scale (VAS) was added to the end of the questionnaire to rate overall satisfaction with life $(0=$ extremely dissatisfied, $100=$ extremely satisfied). Subsequently, a pilot study was conducted with $24 \mathrm{CH}$ patients to assess the face validity and clarity, and the questionnaire was then adjusted accordingly and reduced to 47-items.

\section{Item reduction and scale development}

There were two sources of $\mathrm{CH}$ participants for this study: (i) Patients with a diagnosis of $\mathrm{CH}$ attending the headache clinic at The National Hospital for Neurology and Neurosurgery, London and (ii) an invitation letter to participate in the survey was posted out to $\mathrm{CH}$ participants via OUCH UK (The Organisation for the Understanding of Cluster Headache, United Kingdom). Those who responded to the invitation letter were contacted via telephone and had their headaches phenotyped via a telephone interview. Inclusion criteria for the study were those who had a clinical diagnosis of $\mathrm{CH}$, whilst the exclusion criteria were those who had other major neurological, psychiatric or physical illness. A booklet of questionnaires, which included the 47-item $\mathrm{CH}$-QoL questionnaire was then given or posted out to all participants who satisfied the ICHD-II diagnostic criteria for $\mathrm{CH}(n=521)$ from 2011 to 2013. Details on demographics, headache history and characteristics were collected from the questionnaires. A number of other frequently utilised generic or headache specific QoL instruments were also included in the booklet to allow assessment of convergent validity of this new scale, including the SF-36 Health Survey Questionnaire, the EuroQoL (EQ-5D) Questionnaire and the Migraine-Specific Quality of Life Questionnaire Version 2.1 (MSQ v2.1).

The SF-36 Health Survey Questionnaire is a generic QoL measure with excellent reliability and validity [24]. It contains 36 self-administered items, measuring functions in eight domains; physical functioning (PF), rolephysical (RP), bodily pain (BP), general health $(\mathrm{GH})$, 
vitality (VT), social role functioning (SF), emotional role functioning (EF) and mental health (MH). The subscales are scored on a scale of 0 to 100 , with higher scores indicating better QoL in the domain being measured [24].

The EuroQoL (EQ-5D) Questionnaire is a generic measure of current health status. It consists of five domains: mobility, self-care, usual activities, pain/discomfort and anxiety/depression. In addition, there is a visual analogue scale, with 0 being the worst imaginable and 100 being the best imaginable current health state [19].

The Migraine-Specific Quality of Life Questionnaire Version 2.1 (MSQ v2.1) is a 14-item measure specifically developed to assess the QoL in patients with migraine. The items are divided across three domains; role restrictive, role preventive and emotional functioning. This questionnaire has been shown to have good internal consistency and construct validity [17]. The total possible score ranges from 14 to 84, with higher scores indicating poorer QoL.

A total of 406 completed questionnaires were received, giving a response rate of $77.9 \%$. From this total, $36.5 \%$ were recruited from the headache clinic and $63.5 \%$ were recruited from $\mathrm{OUCH}$ UK. About fifty-nine percent of the responders had episodic $\mathrm{CH}$ and $41.1 \%$ had chronic $\mathrm{CH}$. The mean age of the study sample was 52.4 years (range 20.5-84.4). There were 68.2\% males and $31.8 \%$ females, with a mean age of onset of $\mathrm{CH}$ of 33.0 years (range 8.0-69.0).

Intercorrelation between variables was performed on the data generated from the survey. Items that showed low intercorrelations $(r<0.1)$ were excluded as this demonstrated that they were poorly correlated with the underlying scale. On the other hand, any items that showed high intercorrelations $(r>0.7)$ [6] were examined and the least clinically sensible item was excluded, as theoretically items that correlated too highly are measuring the same underlying dimension [8].

\section{Scale validation and reliability testing}

Construct validity was assessed with an exploratory factor analysis to determine the key components of the 47item questionnaire. Oblique rotation was used for the analysis, as we had reason to believe that the resulting factors would correlate with each other. An eigenvalue cut off point $>1$ was used to extract underlying factors. Concurrent validity was assessed by measuring the Pearson's correlation of the underlying subscales of the $\mathrm{CH}$ specific HRQoL questionnaire with the subscales of SF36 and MSQ v2.1. Meanwhile, Spearman's correlation test was employed to assess validity of the questionnaire and the EQ-5D, due to the ordinal nature of the latter.

A second copy of the 47-item questionnaire was sent out to 75 respondents (approximately $15 \%$ of the main validation sample size) two weeks after the first completion of it to allow assessment of the test-retest reliability of the new scale. Fifty-six completed questionnaires were received (71.7 \% response rate) for the assessment of test-retest reliability. The mean age of this subsample was 55.7 years (range 34.7-79.1). There were $66.1 \%$ males and $33.9 \%$ females, with a mean age of onset of $\mathrm{CH}$ of 36.4 years (range 12.0-66.0).

\section{Results \\ Participants}

There were no significant differences in the sociodemographic and headache characteristics of the participants based on the source of their recruitment, as shown in Table 1. Moreover, no significant differences were found in the $\mathrm{CH}$-specific HRQoL scores between males and females.

\section{Construct validity}

The exploratory factor analysis produced five factors, consisting of 37 items. One factor with an eigenvalue of 1.11 (explaining $3.1 \%$ of the variance) was removed as it only had one item loading onto it and therefore was considered insufficient to produce a meaningful subscale [22]. The remaining factors and items were then examined to determine if there was any scope for further reduction of the number of items to produce a more meaningful and user-friendly scale. Eight items were omitted as they failed to gain significant loading $(>0.4)$ on any of the factors created. This resulted in a 28 -item questionnaire (CHQ), which explained $56.1 \%$ of the variance (Table 2). The Cronbach's alpha was calculated and compared for the factors prior to, and after removal of these items, to ensure that it did not compromise the internal consistency of the scale [4]. Expert opinion was also sought throughout this process to ensure there was no removal of clinically relevant items.

Based on the results of the factor analysis, nine items were grouped onto a factor addressing various 'Restrictions of activities of daily living' (ADL), such as avoiding leaving the house, making plans and inability to complete duties at work. Twelve items described 'Impact on mood and interpersonal relationships', such as feelings of being dismissed by others and worthlessness, including any suicidal tendencies. Two items loaded on a 'Pain and anxiety' factor, which addressed the pain of the cluster headache and any associated anxiety such as dreading that the headache not going away. Finally, a 'Lack of vitality' (five items) factor addresses problems related to energy and cognition, for example difficulties in thinking clearly and concentration. There was good intercorrelation between the subscales (range 0.52-0.75) derived from the factor analysis, supporting internal construct validity. There was also a moderate correlation between the total score and the VAS $(r=-0.57, p<0.01)$. This 
Table 1 Sociodemographic and headache characteristics of the participants based on method of recruitment

\begin{tabular}{|c|c|c|c|c|}
\hline Characteristic & $\begin{array}{l}\text { Total } \\
(n=406)\end{array}$ & $\begin{array}{l}\text { NHNN } \\
(n=148)\end{array}$ & $\begin{array}{l}\text { OUCH UK } \\
(n=258)\end{array}$ & $p$ values* \\
\hline Age, mean \pm SD & $52.4 \pm 12.3$ & $51.1 \pm 12.1$ & $53.2 \pm 12.4$ & 0.109 \\
\hline Gender (male: female) & 2.1: 1 & 2.2: 1 & 2.1: 1 & 0.820 \\
\hline Marital status, $n(\%)$ & & & & 0.079 \\
\hline Single & $60(14.9 \%)$ & $25(16.9 \%)$ & 35 (13.7\%) & \\
\hline Married/cohabiting & $304(75.2 \%)$ & $103(69.6 \%)$ & $201(78.5 \%)$ & \\
\hline Widowed & $12(3.0 \%)$ & $4(2.7 \%)$ & $8(3.1 \%)$ & \\
\hline Divorced/separated & $28(6.9 \%)$ & $16(10.8 \%)$ & $12(4.7 \%)$ & \\
\hline Years of education, $n(\%)$ & & & & 0.122 \\
\hline $1-11$ & $109(27.4 \%)$ & $45(31.0 \%)$ & $64(25.3 \%)$ & \\
\hline $12-13$ & $73(18.3 \%)$ & $32(22.1 \%)$ & $41(16.2 \%)$ & \\
\hline $14-17$ & $167(42.0 \%)$ & $55(37.9 \%)$ & $112(44.3 \%)$ & \\
\hline $18+$ & $49(12.3 \%)$ & $13(9.0 \%)$ & $36(14.2 \%)$ & \\
\hline Smokers, n (\%) & $186(45.8 \%)$ & $70(47.2 \%)$ & $116(45.0 \%)$ & 0.649 \\
\hline Duration since onset of $\mathrm{CH}$ (years), mean $\pm \mathrm{SD}$ & $19.3 \pm 11.5$ & $18.8 \pm 10.7$ & $19.6 \pm 12.0$ & 0.483 \\
\hline Duration of $\mathrm{CH}$ (minutes), mean $\pm \mathrm{SD}$ & $46.5 \pm 58.8$ & $48.6 \pm 52.9$ & $45.2 \pm 62.1$ & 0.601 \\
\hline Frequency of $\mathrm{CH}$ attacks (number/day), mean $\pm \mathrm{SD}$ & $3.5 \pm 2.4$ & $3.5 \pm 2.1$ & $3.5 \pm 2.5$ & 0.892 \\
\hline Severity of $\mathrm{CH}$ attacks, $n(\%)$ & & & & 0.057 \\
\hline Mild & $1(0.2 \%)$ & $1(0.7 \%)$ & $0(0.0 \%)$ & \\
\hline Moderate & $15(3.7 \%)$ & $9(6.1 \%)$ & $6(2.3 \%)$ & \\
\hline Severe & $29(7.1 \%)$ & $15(10.1 \%)$ & $14(5.4 \%)$ & \\
\hline Very severe & $61(15.0 \%)$ & $20(13.5 \%)$ & $41(15.9 \%)$ & \\
\hline Excruciating & $300(73.9 \%)$ & $103(69.6 \%)$ & $197(76.4 \%)$ & \\
\hline
\end{tabular}

NHNN The National Hospital for Neurology and Neurosurgery, OUCH UK The Organisation for the Understanding of Cluster Headache, United Kingdom, $\mathrm{CH}$ cluster headache, $S D$ standard deviation

*Based on two-sample $t$-tests for continuous variables and Chi-square tests for categorical variables

negative correlation was expected as their scores ran in opposite direction (higher VAS indicates better HRQoL whereas higher total score indicates poorer HRQoL).

\section{Internal consistency and test-retest reliability}

The scale had a Cronbach's coefficient alpha $(\alpha)$ of 0.95 , which was well above the recommended criteria of 0.70 . The internal consistency and corrected item to total correlations of the items to their resulting subscale is shown in Table 3. Test-retest reliability testing of the scales was performed on the data collected from respondents who completed the questionnaire on two occasions, which showed significant correlation between the two assessment occasions (intra class correlation coefficient was 0.87). Cronbach's alpha was also satisfactory for the scales on both occasions (Table 4).

\section{Convergent validity}

The scale was assessed for convergent validity by measuring correlation of the subscales with the relevant subscales of the EQ-5D, SF-36 and MSQ (Table 5). With regards to the EQ-5D, the CHQ subscales showed low to moderate correlations with all of the EQ-5D domains, except for the pain and anxiety subscale of CHQ and the mobility and self-care domains (EQ-5D). The highest correlation observed was between the 'Impact on mood and interpersonal relationships' subscale of the CHQ and anxiety/depression item of the EQ-5D $\left(r_{s}=0.54, p<0.01\right)$.

Similarly, there were low to moderate correlations with the SF-36 and MSQ subscales. The 'Restrictions of ADL' factor of $\mathrm{CHQ}$ correlated significantly with the social role functioning (SF) $(r=-0.47, p<0.01)$ and emotional role functioning (RE) subscales $(r=-0.41, p<0.01)$. The 'Impact on mood and interpersonal relationships' subscale of the CHQ correlated highly with mental health $(\mathrm{MH})(r=-0.67, p<0.01)$ and moderately with SF $(r=-0.52, p<0.01), \operatorname{RE}(r=-0.50, p<0.01)$ and vitality (VT) $(r=-0.49, p<0.01)$ subscales. The 'Lack of vitality' subscale of the CHQ correlated moderately with VT $(r=-0.43, p<0.01)$ and RE $(r=-0.39, p<0.01)$. All the correlations were negative as the CHQ and SF-36 were scored in different directions. In relation to the MSQ, the CHQ subscales correlated significantly with 
Table 2 Results of the principal component factor analysis of the CHQ scale

\begin{tabular}{|c|c|c|c|c|}
\hline Items & $\begin{array}{l}\text { Factor } 1 \\
\text { Restriction } \\
\text { of } A D L\end{array}$ & $\begin{array}{l}\text { Factor } 2 \\
\text { Impact on } \\
\text { mood and } \\
\text { interpersonal } \\
\text { relationships }\end{array}$ & $\begin{array}{l}\text { Factor } 3 \\
\text { Pain and } \\
\text { anxiety }\end{array}$ & $\begin{array}{l}\text { Factor } 4 \\
\text { Lack of } \\
\text { vitality }\end{array}$ \\
\hline Avoided leaving the house & 0.76 & & & \\
\hline Avoided making plans due to unpredictability of $\mathrm{CH}$ e.g., holidays & 0.72 & & & \\
\hline Felt unable to complete duties at work & 0.66 & & & \\
\hline Had difficulty in getting involved in leisure activities e.g., cinema, theatre, etc.? & 0.63 & & & \\
\hline Avoided crowded and noisy places e.g., public transport, pubs, etc. & 0.57 & & & \\
\hline Felt that the severity of cluster headache affected your daily activities & 0.56 & & & \\
\hline Been less involved in family affairs e.g., interaction with children, planning holidays & 0.54 & & & \\
\hline Been unable to socialise/spend time with friends and family & 0.46 & & & \\
\hline Been unable to achieve your daily goals and carry out routines and chores & 0.42 & & & \\
\hline Felt less respected by others & & 0.89 & & \\
\hline Had problems with close personal relationship & & 0.73 & & \\
\hline Felt you were a burden on family and friends & & 0.71 & & \\
\hline $\begin{array}{l}\text { Felt self-conscious and uncomfortable about your appearance after a cluster } \\
\text { headache attack (e.g., swelling/redness of eyes and facial sweating, etc.) }\end{array}$ & & 0.68 & & \\
\hline Felt that others are dismissive of your cluster headaches & & 0.61 & & \\
\hline Felt aggressive & & 0.53 & & \\
\hline Felt bad about yourself, lost self-confidence or felt worthless & & 0.53 & & \\
\hline Felt like harming yourself or suicidal & & 0.53 & & \\
\hline Been irritable, impatient or less tolerant & & 0.53 & & \\
\hline Been forgetful e.g., missed appointments & & 0.49 & & \\
\hline $\begin{array}{l}\text { Been unable to take care of your appearance (e.g., take a bath, put make-up on, change } \\
\text { clothes etc.) }\end{array}$ & & 0.49 & & \\
\hline Felt isolated, lonely or vulnerable & & 0.45 & & \\
\hline Found your pain is unbearable if untreated & & & 0.67 & \\
\hline Dreaded that the headache would not go away & & & 0.48 & \\
\hline Felt lacking in energy and constantly tired & & & & -0.88 \\
\hline Felt sleepy, worn out or less able to concentrate due to nocturnal attacks of $\mathrm{CH}$ & & & & -0.72 \\
\hline Had problems concentrating e.g., reading paper, watching TV, etc. & & & & -0.62 \\
\hline Been unable to think clearly & & & & -0.60 \\
\hline Felt tense or anxious & & & & -0.48 \\
\hline$\%$ of variance explained & 43.11 & 5.59 & 4.06 & 3.38 \\
\hline
\end{tabular}

CHQ cluster headache specific quality of life, $A D L$ activities of daily living

the all domains. Furthermore, the 'Impact on mood and interpersonal relationships' subscale of the CHQ and emotional functioning domain of the MSQ were well correlated $(r=0.65, p<0.01)$, supporting good convergent validity.

The mean scores of the $\mathrm{CHQ}$ in episodic $\mathrm{CH}$ patients were then compared to those of chronic $\mathrm{CH}$ patients. Patients with chronic $\mathrm{CH}$ had significantly greater impairment in their QoL compared to their episodic counterparts $(61.6 \pm 18.9$ vs $56.2 \pm 19.0, p=0.010)$, further supporting good validity and sensitivity of the questionnaire to detect impairment specifically related to $\mathrm{CH}$.

\section{Discussion}

Several studies have demonstrated that QoL is significantly impaired in patients with $\mathrm{CH}$, more so in chronic sufferers, with considerable impact on daily living e.g., efficiency and ability to work and social functioning, with almost $20 \%$ of patients losing their jobs secondary to the disorder $[5-7,13,15,20,21]$. However, these studies have all used either generic QoL scales such as the SF-36, or migraine-specific scales that may not necessarily be able to capture the true effects of $\mathrm{CH}$, and may therefore be underestimating the actual impact of the disorder on QoL. Indeed, some instruments specifically 
Table 3 Item to total correlations and Cronbach's alpha for the CHQ scale

\begin{tabular}{|c|c|c|}
\hline Scale/Items & $\begin{array}{l}\text { Corrected item } \\
\text { to total correlation }\end{array}$ & Cronbach's alpha \\
\hline Restriction of $\mathrm{ADL}$ & & 0.91 \\
\hline Avoided leaving the house & 0.67 & \\
\hline Avoided making plans due to unpredictability of $\mathrm{CH}$ e.g., holidays & 0.66 & \\
\hline Felt unable to complete duties at work & 0.70 & \\
\hline Had difficulty in getting involved in leisure activities e.g., cinema, theatre, etc.? & 0.78 & \\
\hline Avoided crowded and noisy places e.g., public transport, pubs, etc. & 0.63 & \\
\hline Felt that the severity of cluster headache affected your daily activities & 0.68 & \\
\hline Been less involved in family affairs eg interaction with children,planning holidays & 0.67 & \\
\hline Been unable to socialise/spend time with friends and family & 0.73 & \\
\hline Been unable to achieve your daily goals and carry out routines and chores & 0.69 & \\
\hline Impact on mood and interpersonal relationships & & 0.90 \\
\hline Felt less respected by others & 0.72 & \\
\hline Had problems with close personal relationship & 0.71 & \\
\hline Felt you were a burden on family and friends & 0.73 & \\
\hline $\begin{array}{l}\text { Felt self-conscious and uncomfortable about your appearance after a cluster headache attack } \\
\text { (eg swelling/redness of eyes and facial sweating, etc.) }\end{array}$ & 0.65 & \\
\hline Felt that others are dismissive of your cluster headaches & 0.50 & \\
\hline Felt aggressive & 0.59 & \\
\hline Felt bad about yourself, lost self-confidence or felt worthless & 0.63 & \\
\hline Felt like harming yourself or suicidal & 0.59 & \\
\hline Been irritable, impatient or less tolerant & 0.63 & \\
\hline Been forgetful e.g., missed appointments & 0.58 & \\
\hline Been unable to take care of your appearance (eg take a bath, put make-up on, change clothes etc.) & 0.55 & \\
\hline Felt isolated, lonely or vulnerable & 0.71 & \\
\hline Pain and anxiety & & 0.52 \\
\hline Found your pain is unbearable if untreated & 0.37 & \\
\hline Dreaded that the headache would not go away & 0.37 & \\
\hline Lack of vitality & & 0.85 \\
\hline Felt lacking in energy and constantly tired & 0.69 & \\
\hline Felt sleepy, worn out or less able to concentrate due to nocturnal attacks of $\mathrm{CH}$ & 0.61 & \\
\hline Had problems concentrating e.g., reading paper, watching TV, etc. & 0.64 & \\
\hline Been unable to think clearly & 0.70 & \\
\hline Felt tense or anxious & 0.66 & \\
\hline
\end{tabular}

Table 4 Cronbach's alpha and test-retest reliability at the first and second assessment occasions

\begin{tabular}{lccl}
\hline Scale & $\begin{array}{c}\text { Cronbach's } \\
\text { alpha time 1 }\end{array}$ & $\begin{array}{c}\text { Cronbach's } \\
\text { alpha time 2 } 2\end{array}$ & $\begin{array}{l}\text { Test-retest } \\
\text { reliability }\end{array}$ \\
\hline Restriction of ADL & 0.91 & 0.93 & $0.84 p<0.01$ \\
$\begin{array}{l}\text { Impact on mood and } \\
\text { interpersonal relationships }\end{array}$ & 0.90 & 0.87 & $0.83 p<0.01$ \\
Pain and anxiety & 0.52 & 0.63 & $0.71 p<0.01$ \\
Lack of vitality & 0.85 & 0.80 & $0.80 p<0.01$ \\
\hline
\end{tabular}

ask about suffering in the past four weeks, thus ECH sufferers out of a bout would rate low scores on these scales, even though they may be severely impaired during a bout [9]. Hence, these measures may not provide a true reflection of the actual impairment. Moreover, issues that are specific to $\mathrm{CH}$ are not addressed through the use of these scales, for example suicidal tendencies, which is prevalent among $\mathrm{CH}$ sufferers. Circadian periodicity is another distinct feature in this disorder, with sufferers usually being woken up around the same time every night, at the onset 
Table 5 Correlation coefficients ( $p$ values) between the CHQ subscales and the EQ-5D and SF-36 generic and MSQ v2.1 migraine-specific quality of life measures

\begin{tabular}{|c|c|c|c|c|}
\hline & Restriction of ADL & Impacts on mood and interpersonal relationships & Pain and anxiety & Lack of vitality \\
\hline \multicolumn{5}{|l|}{$E Q-5 D$} \\
\hline Mobility & $0.28^{\mathrm{a}}$ & $0.27^{\mathrm{a}}$ & $0.07^{c}$ & $0.21^{\mathrm{a}}$ \\
\hline Self-care & $0.31^{\mathrm{a}}$ & $0.39^{\mathrm{a}}$ & $0.10^{\mathrm{b}}$ & $0.27^{\mathrm{a}}$ \\
\hline Usual activities & $0.35^{\mathrm{a}}$ & $0.43^{\mathrm{a}}$ & $0.14^{\mathrm{a}}$ & $0.29^{\mathrm{a}}$ \\
\hline Pain/discomfort & $0.19^{\mathrm{a}}$ & $0.30^{\mathrm{a}}$ & $0.11^{\mathrm{b}}$ & $0.14^{\mathrm{a}}$ \\
\hline Anxiety/depression & $0.39^{a}$ & $0.54^{\mathrm{a}}$ & $0.28^{\mathrm{a}}$ & $0.38^{\mathrm{a}}$ \\
\hline \multicolumn{5}{|l|}{ SF-36 } \\
\hline Physical functioning (PF) & $-0.27^{\mathrm{a}}$ & $-0.37^{\mathrm{a}}$ & $-0.11^{b}$ & $-0.24^{\mathrm{a}}$ \\
\hline Role physical (RP) & $-0.23^{\mathrm{a}}$ & $-0.32^{\mathrm{a}}$ & $-0.05^{c}$ & $-0.19^{a}$ \\
\hline Bodily pain (BP) & $-0.23^{a}$ & $-0.31^{\mathrm{a}}$ & $-0.12^{b}$ & $-0.22^{\mathrm{a}}$ \\
\hline General health $(\mathrm{GH})$ & $-0.34^{a}$ & $-0.46^{\mathrm{a}}$ & $-0.15^{\mathrm{a}}$ & $-0.32^{\mathrm{a}}$ \\
\hline Vitality (VT) & $-0.37^{\mathrm{a}}$ & $-0.49^{\mathrm{a}}$ & $-0.22^{\mathrm{a}}$ & $-0.43^{\mathrm{a}}$ \\
\hline Social functioning (SF) & $-0.47^{\mathrm{a}}$ & $-0.52^{\mathrm{a}}$ & $-0.21^{\mathrm{a}}$ & $-0.37^{\mathrm{a}}$ \\
\hline Role emotional (RE) & $-0.41^{a}$ & $-0.50^{\mathrm{a}}$ & $-0.21^{\mathrm{a}}$ & $-0.39^{a}$ \\
\hline Mental health (MH) & $-0.51^{a}$ & $-0.67^{\mathrm{a}}$ & $-0.37^{\mathrm{a}}$ & $-0.50^{\mathrm{a}}$ \\
\hline \multicolumn{5}{|l|}{ MSQ v2.1 } \\
\hline Role restrictive (RR) & $0.51^{\mathrm{a}}$ & $0.53^{\mathrm{a}}$ & $0.29^{a}$ & $0.45^{\mathrm{a}}$ \\
\hline Role preventive (RP) & $0.56^{\mathrm{a}}$ & $0.52^{\mathrm{a}}$ & $0.28^{\mathrm{a}}$ & $0.42^{\mathrm{a}}$ \\
\hline Emotional functioning (EF) & $0.49^{\mathrm{a}}$ & $0.65^{\mathrm{a}}$ & $0.41^{\mathrm{a}}$ & $0.47^{\mathrm{a}}$ \\
\hline
\end{tabular}

${ }^{\mathrm{a}} p<.01^{\mathrm{b}} p<.05:{ }^{\mathrm{c}}$ non-significant

of rapid eye movement (REM) sleep, which can have a major impact on patients with $\mathrm{CH}$. We have therefore developed a questionnaire based on both patient and expert views of the disorder. To our knowledge, this is the first scale developed to measure QoL specifically in $\mathrm{CH}$ sufferers.

In the current study, we developed and validated a $\mathrm{CH}$-specific QoL scale, the CHQ. Items for the scale were generated from an in-depth literature review and semi-structured patient interviews, allowing $\mathrm{CH}$ sufferers to express their views about the various aspects of their lives that they felt were affected by the disorder and should be highlighted in such a disease specific QoL scale. This was followed by a review by a panel of experts with an interest in headaches to include items that were considered clinically relevant. These steps allowed us to develop a scale that is based on both patient and clinician input, thus ensuring good content and face validity. Furthermore, following administration to a large sample of participants with $\mathrm{CH}$, the scale has also been shown to have good construct validity, internal consistency and test-retest reliability. In terms of convergent validity, the subscale scores showed good correlation with those of other widely used QoL scales that have already been shown to have good validity and reliability, specifically the EQ-5D, SF-36 and MSQ. Moreover, the scale has been able to detect significantly greater impairment in QoL in chronic $\mathrm{CH}$ patients, compared to episodic $\mathrm{CH}$ patients, thus showing good sensitivity.

A limitation of this study was that about a third of our study population comprised patients attending a tertiary referral centre; hence medically intractable cases may be over-represented in our sample. Of the 148 patients recruited from the headache clinic, $64.2 \%$ had chronic $\mathrm{CH}$, which is significantly greater than is expected in the general population [1]. Thus our sample may not be totally representative of the $\mathrm{CH}$ population in the community. However, this bias enabled us to collect data from a fair proportion of chronic $\mathrm{CH}$ sufferers $(42.9 \%)$, who due to the recurring nature of their headaches are likely to be more disabled by this disorder, giving us a better picture of the extent of the impact on patients QoL. Since the development of the questionnaire involved both $\mathrm{CH}$ patients and a panel of experts, we strongly believe that the items included in our questionnaire were equally important for both $\mathrm{ECH}$ and $\mathrm{CCH}$ sufferers. Furthermore, despite the different methods of recruitment, it could be argued that those recruited via OUCH UK were also significantly affected by their $\mathrm{CH}$ to warrant them to seek help, as shown by the lack of significant differences in their headache characteristics from those recruited through the hospital, hence, supporting our decision to group them together. 


\section{Conclusions}

We have developed the first objective measure of QoL specifically for $\mathrm{CH}$ sufferers, which we have intended to be brief and user-friendly as it takes about $10 \mathrm{~min}$ to complete the questionnaire. We hope that it can be used in the clinical setting to monitor QoL as part of patient care, as well as in clinical trials as a patient-reported outcome measure. The next stage in the validation of the CHQ will be an assessment of its sensitivity to capture change in QoL over time (e.g., in the active and remission phases in episodic $\mathrm{CH}$ ) and following medical and surgical treatments of $\mathrm{CH}$. Further studies will also need to be performed in other community populations as the development and validation of this scale was based solely on a sample of $\mathrm{CH}$ population in the United Kingdom. Future studies could also examine age or gender related differences in QoL in $\mathrm{CH}$ with the CHQ. Once the CHQ has been fully validated and its sensitivity to change established, it could serve as an appropriate measure for identifying the demographic (e.g., age, gender, socioeconomic status), clinical (e.g., severity of pain, frequency of episodes, distribution of pain), psychological (mood, anxiety), social (e.g., social support) and behavioural (e.g., ways of coping, avoidance) factors that predict QoL in $\mathrm{CH}$. Such information would be valuable in steering clinical management to focus on aspects of the disease that would help enhance QoL of $\mathrm{CH}$ sufferers.

\section{Acknowledgements}

The authors would like to thank Mr Manoharan Andiappan for his statistical input and all the patients who participated in this study.

\section{Authors' contributions \\ NAB was involved in data collection, data analysis, scale development and drafting and review of the manuscript. MT was involved in data collection, data analysis, scale development and review of the manuscript. ST was involved in data collection, scale development and review of the manuscript. $\mathrm{GL}$ was involved in data analysis and review of the manuscript. MM was involved in conceptualization of the study, scale development and review of the manuscript. MJ was involved in conceptualization of the study, data analysis, scale development, and drafting and review of the manuscript. All authors read and approved the final manuscript.}

\section{Competing interests}

Dr Abu Bakar, Ms Torkamani, Dr Tanprawate, Dr Lambru and Prof Jahanshahi declare no competing interests.

Dr Matharu serves on the advisory board for Allergan and St Jude Medical, and has received payment for the development of educational presentations from Allergan, Merck Sharpe and Dohme Ltd and Medtronic.

\section{Ethics approval and consent to participate}

Ethical approval for this study was obtained from The North West London Research Ethics Committee. Informed written consent was obtained from all participants prior to enrolment in the study.

\footnotetext{
Author details

${ }^{1}$ Headache Group, UCL Institute of Neurology and The National Hospital for Neurology and Neurosurgery, Queen Square, London WC1N 3BG, UK. ${ }^{2}$ Cognitive Motor Neuroscience Group, Sobell Department of Motor Neuroscience \& Movement Disorders, UCL Institute of Neurology and The National Hospital for Neurology and Neurosurgery, Queen Square, London WC1N 3BG, UK.
}

Received: 22 June 2016 Accepted: 1 September 2016

Published online: 05 September 2016

\section{References}

1. Bahra A, May A, Goadsby PJ (2002) Cluster headache: a prospective clinical study with diagnostic implications. Neurology 58(3):354-361

2. Bussone G, Usai S, Grazzi L, Rigamonti A, Solari A, D'Amico D (2004) Disability and quality of life in different primary headaches: results from Italian studies. Neurol Sci 25:s105-s107. doi:10.1007/s10072-004-0263-y

3. Cavanna AE, Schrag A, Morley D, Orth M, Robertson MM, Joyce E, Critchley HD, Selai C (2008) The Gilles de la Tourette syndrome-quality of life scale (GTS-QOL): development and validation. Neurology 71(18):1410-1416. doi:10.1212/01.wnl.0000327890.02893.6171/18/1410

4. Cronbach $L$ (1951) Coefficient alpha and the internal structure of tests. Psychometrika 16(3):297-334. doi:10.1007/bf02310555

5. D'Amico D, Rigamonti A, Solari A, Leone M, Usai S, Grazzi L, Bussone G (2002) Health-related quality of life in patients with cluster headache during active periods. Cephalalgia 22(10):818-821

6. Donnet A, Lanteri-Minet M, Guegan-Massardier E, Mick G, Fabre N, Geraud G, Lucas C, Navez M, Valade D (2007) Chronic cluster headache: a French clinical descriptive study. J Neurol Neurosurg Psychiatry 78(12):1354-1358. doi:10.1136/jnnp.2006.112037

7. Ertsey C, Manhalter N, Bozsik G, Afra J, Jelencsik I (2004) Health-related and condition-specific quality of life in episodic cluster headache. Cephalalgia 24(3):188-196

8. Field AP (2009) Discovering statistics using SPSS. Sage, Los Angeles; London

9. Gaul C, Finken J, Biermann J, Mostardt S, Diener HC, Müller O, Wasem J, Neumann A (2011) Treatment costs and indirect costs of cluster headache: a health economics analysis. Cephalalgia 31(16):1664-1672. doi:10.1177/ 0333102411425866

10. Goadsby P, Cohen A, Matharu M (2007) Trigeminal autonomic cephalalgias: diagnosis and treatment. Curr Neurol Neurosci Rep 7(2):117-125. doi:10. 1007/s11910-007-0006-6

11. Hartmaier SL, Santanello NC, Epstein RS, Silberstein SD (1995) Development of a brief 24-hour migraine-specific quality of life questionnaire. Headache 35(6):320-329. doi:10.1111/j.1526-4610.1995.hed3506320.x

12. Headache Classification Subcommittee of the International Headache Society (2004) The International Classification of Headache Disorders: 2nd edition. Cephalalgia 24(Suppl 1):9-160

13. Jensen RM, Lyngberg A, Jensen RH (2007) Burden of cluster headache. Cephalalgia 27(6):535-541. doi:10.1111/j.1468-2982.2007.01330.x

14. Jhingran P, Osterhaus JT, Miller DW, Lee JT, Kirchdoerfer L (1998) Development and validation of the migraine-specific quality of life questionnaire. Headache 38(4):295-302. doi:10.1046/j.1526-4610.1998. 3804295.x

15. Jürgens TP, Gaul C, Lindwurm A, Dresler T, Paelecke-Habermann $Y$, SchmidtWilcke T, Lürding R, Henkel K, Leinisch E (2011) Impairment in episodic and chronic cluster headache. Cephalalgia 31(6):671-682. doi:10.1177/ 0333102410391489

16. Luerding R, Henkel K, Gaul C, Dresler T, Lindwurm A, Paelecke-Habermann Y, Leinisch E, Jürgens TP (2012) Aggressiveness in different presentations of cluster headache: results from a controlled multicentric study. Cephalalgia 32(7):528-536. doi:10.1177/0333102412443336

17. Martin BC, Pathak DS, Sharfman MI, Adelman JU, Taylor F, Kwong WJ, Jhingran P (2000) Validity and Reliability of the Migraine-Specific Quality of Life Questionnaire (MSQ Version 2.1). Headache 40(3):204-216. doi:10.1046/j. 1526-4610.2000.00030.x

18. Peto V, Jenkinson C, Fitzpatrick R, Greenhall R (1995) The development and validation of a short measure of functioning and well being for individuals with Parkinson's disease. Qual Life Res 4(3):241-248

19. Rabin R, de Charro F (2001) EQ-5D: a measure of health status from the EuroQol Group. Ann Med 33(5):337-343

20. Rozen TD, Fishman RS (2012) Cluster headache in the United States of America: demographics, clinical characteristics, triggers, suicidality, and personal burden. Headache 52(1):99-113. doi:10.1111/j.1526-4610.2011. 02028.x

21. Solomon GD, Skobieranda FG, Gragg LA (1994) Does quality of life differ among headache diagnoses? Analysis using the medical outcomes study instrument. Headache 34(3):143-147

22. Velicer WF FJ (1998) Affects of variable and subject sampling on factor pattern recovery. 3:231-251. doi:10.1037/1082-989x.3.2.231 
23. Wagner TH, Patrick DL, Galer BS, Berzon RA (1996) A New instrument to assess the long-term quality of life effects from migraine: development and psychometric testing of the MSQOL. Headache 36(8):484-492. doi:10.1046/j. 1526-4610.1996.3608484.x

24. Ware JE Jr, Gandek B (1998) Overview of the SF-36 Health Survey and the International Quality of Life Assessment (IQOLA) Project. J Clin Epidemiol 51(11):903-912, http://dx.doi.org/10.1016/S0895-4356(98)00081-X

\section{Submit your manuscript to a SpringerOpen ${ }^{\oplus}$ journal and benefit from:}

- Convenient online submission

- Rigorous peer review

- Immediate publication on acceptance

- Open access: articles freely available online

- High visibility within the field

- Retaining the copyright to your article

Submit your next manuscript at springeropen.com 